\title{
A Model of time Variability of Characteristic Parameters of the Water Distribution System as a Base of Information and the Basis of Mathematical Modelling
}

\author{
Agnieszka Trębicka' \\ 1 Department of Technology and Systems of Environmental Engineering, Bialystok University of Technology, \\ ul. Wiejska 45E, 15-351 Bialystok, Poland \\ e-mail: a.trebicka@pb.edu.pl
}

\begin{abstract}
The subject of the paper is the Bialystok water supply network. The studies on the Bialystok water supply network are aimed at identifying new, more rational ways of operation (decreasing the pressure value) and defining the conditions for expansion and modernization of the water supply network, with the particular system analysis as a part of identifying the most dangerous places on the network. The increase of requirements concerning the quality and the time of realisation in the scope of the design studies requires the introduction of computer technology in calculations. The work presents the processes based on mapping and refinement of specific conservative states of the water distribution system (SDW), using mathematical modelling taking into account the latest available computer techniques.
\end{abstract}

Keywords: computer simulation, distribution systems, water supply network, mathematical model, dynamic model, computer modelling

\section{INTRODUCTION}

The basis for conducting the computer simulations in a normal operation as well as in emergency situations of the analysed water distribution system, is the need to examine the ability of the system to change hydraulic parameters: flow rate and water pressure, assuming that SDW works as a variable system over time. Therefore, special attention has been paid to the temporary variability of water movement. Therefore, the time factor was taken into account and selected situations where the system works under emergency conditions, which most often causes the system to malfunction and, above all, causes a shortage in water supply, were analysed [Darson et al. 2007]. The failure time (event) as well as its duration, are of particular importance for determining the negative consequences of the failure and the effectiveness of possible measures to reduce the severity of these incidents. The ability to map the dynamic nature of the operation of the water distribution system is one of the basic properties that can be obtained using a time-based and a spatial computer simulation. The results obtained through the above-mentioned process allow, in turn, to assess the quality of functioning of the considered model from the point of view of both the user and the operator, which mainly relate to the assessment of the load and reserves of individual systems and facilities [Trębicka 2018].

\section{SPACE-TIME SIMULATION OF BIALYSTOK WATER DISTRIBUTION SYSTEM}

The space-time simulation was carried out by meanas of the ISYDYW software using its calculation module. It enables to create a database, then to schematise the information contained in this database and, based on both parts, generate calculation packages and perform appropriate calculations of water supply systems. The special structural role of the ISYDYW software, which 
enabled to obtain a virtually unlimited number of computational models with different ranges of accuracy and details for the system of water distribution described in the database, should be noted here [Mays 2005]. Each of these models was preceded by a scheme developed in the process of schematisation, which became also a recipe for the extent to which it was used and how the information contained in the database was grouped in the constructed calculation models. The ISYDYW software contains a number of procedures allowing for far advanced automation of the processing and control of the correctness of the entered information, using the graphical capabilities of the current generation of computers to a large extent [Knapik 2000].

\section{DYNAMICS OF THE MATHEMATICAL MODEL OF THE BIALYSTOK WATER DISTRIBUTION SYSTEM IN THE SIMULATION PROCESS}

In order for the SDW model of the city of Bialystok to function, the spatial location of the nodes and pipeline connections was schematised, and their parameters were subsequently defined. The height of the nodes location and the values of the diameters, the absolute roughness coefficient and the local pipeline losses coefficient were determined successively. It was also necessary to determine the roughness coefficient, where specialized tests are required on the specified pipelines of varying diameter and duration of operation [Trębicka 2018]. For each node, it was necessary to determine the value of daily water intake and the current hourly distribution with division into discrete time segments. The calculations were carried out for any fragment or for the whole day with its division into stages. The amount of water intake for each time step was calculated individually for each node, based on the set daily volume of hourly demand for water intake and reduction factor, taking into account the effect of a shortage of pressure in relation to the required value [Studziński 2014, Walski et al. 2011].

The Bialystok water supply network is supplied by $\mathrm{P} 1$ and $\mathrm{P} 2$ pumping stations with different pressure values. The SDW schematisation indicated the need to build a model with 108 nodes and 158 sections. For the demand model, the structural units with residential buildings and the units with an industrial function were taken into account. For each of them, the user structure was established, i.e. the type of building, the sanitary equipment standard, the type and changeability of the industry, and the hourly schedules were defined accordingly.

The mathematical model of the Bialystok water supply network is currently an important source of information about the system being operated, and its dynamic model of the water distribution system has proved particularly useful in diagnosing the state of the operated system and developing the concept for expanding or modernising waterworks (Fig. 1).

\section{TEMPORARY VARIABILITY OF THE BIALYSTOK WATER DISTRIBUTION SYSTEM PARAMETERS DURING COMPUTER SIMULATIONS}

The basis for conducting computer simulations in normal operation as well as in emergency situations of the Bialystok distribution system is the need to examine the ability of the system to change hydraulic parameters: the flow rate and the water pressure, assuming that SDW works as a variable system in time [Abe and Peter 2010, Boulos et al. 2009]. Hence, special attention was paid to the temporary variability of water movement. By considering the time factor, the selected situations when the system operation takes place under emergency conditions, which are most often the cause of the malfunctioning of the system, and above all causes a shortage in water supply, were analysed. The time of failure (event) as well as its duration, are of particular importance for determining the negative consequences of failure and the effectiveness of possible measures to reduce the severity of these incidents. The ability to map the dynamic nature of the operation of the water distribution system is one of the basic properties that can be obtained using a time-based and spatial computer simulation. The results obtained through the above-mentioned process, in turn, allow the assessment of the quality of functioning of the considered model from the point of view of both the user and the operator, which mainly relate to the assessment of the load and reserves of individual systems and facilities [Machón et al. 2007, Michaud et al. 2006]. 


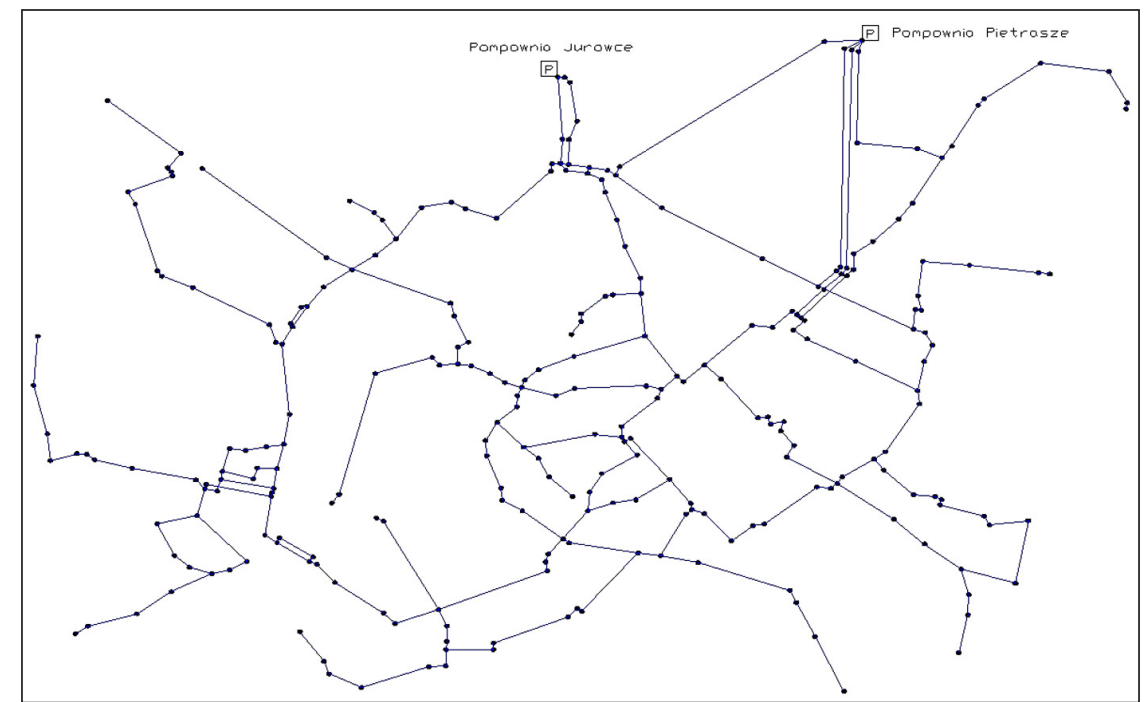

Figure 1. Diagram of the SDW of Bialystok reflecting the variant A (existing state)

\section{ASSESSMENT OF THE FUNCTIONING OF THE CITY WATER DISTRIBUTION SYSTEM IN TERMS OF TIME AND SPACE}

From the entire SDW system, simulation calculations were carried out and included in the form of a series of variants. The results of the calculations obtained using the constructed model of water demand and the computational mathematical model of the analysed SDW of the city of Bialystok were used. They concerned the functioning of SDW. Visible changes were analysed not only in the system element itself, but also in the entire SDW. Each episode of the model has been carefully observed. Each of the analysed series of examinations was carried out for the daily work cycles (from 6 am to $6 \mathrm{pm}$ ) of the SDW corresponding to an average demand period, divided into 15 minute time steps as part of the SDW performance assessment for various assumed cases and for the purpose of impact assessment of the hydraulic events that occurred as a result of the observed changes. The variant mapping the hydraulic system of the water supply network for the existing condition served as a basis for further research and comparisons. From the entire SDW system, the simulation calculations were carried out and included in the form of a series of variants $\mathrm{A}, \mathrm{B}, \mathrm{C}, \mathrm{D}$ and $\mathrm{E}$. The results of the calculations obtained using the constructed water demand model and the mathematical model of the analyses DW of Bialystok city were taken into account. They concerned the functioning of SDW. The ongoing changes were analysed, not only in the system element itself, but also throughout the entire SDW. Each section of the model was subjected to a thorough observation. As not all observed situations brought significant reactions to the model, the most representative ones were selected $[6,8]$. Each of the analysed series of tests was carried out for the daily work cycles (from 6 am to $6 \mathrm{pm}$ ) of SDW corresponding to an average demand period divided into 15 minute time steps as part of the SDW functioning assessment for various assumed cases and to assess the hydraulic effects arising events as a result of the observed changes. The variant A series was designed to map the hydraulic system of the water supply network for the existing condition, which is the basis for the further research and comparisons. The results for this series showed an appropriate level of the system simulating the normal operating conditions of the SDW, constituting a reference level and comparison for the subsequent series B, C, D and $\mathrm{E}$ under consideration.

\section{DISCUSSION OF SIMULATION RESULTS OF THE WATER DISTRIBUTION SYSTEM}

The situations considered were captured in the form of variants, which were separated as a result of testing the entire SDW system, where each segment of the model was subjected to thorough observation, while changes were also observed not only in the system element but also throughout the entire SDW. Due to the fact that SDW has low demand (minimum flow rates), and 


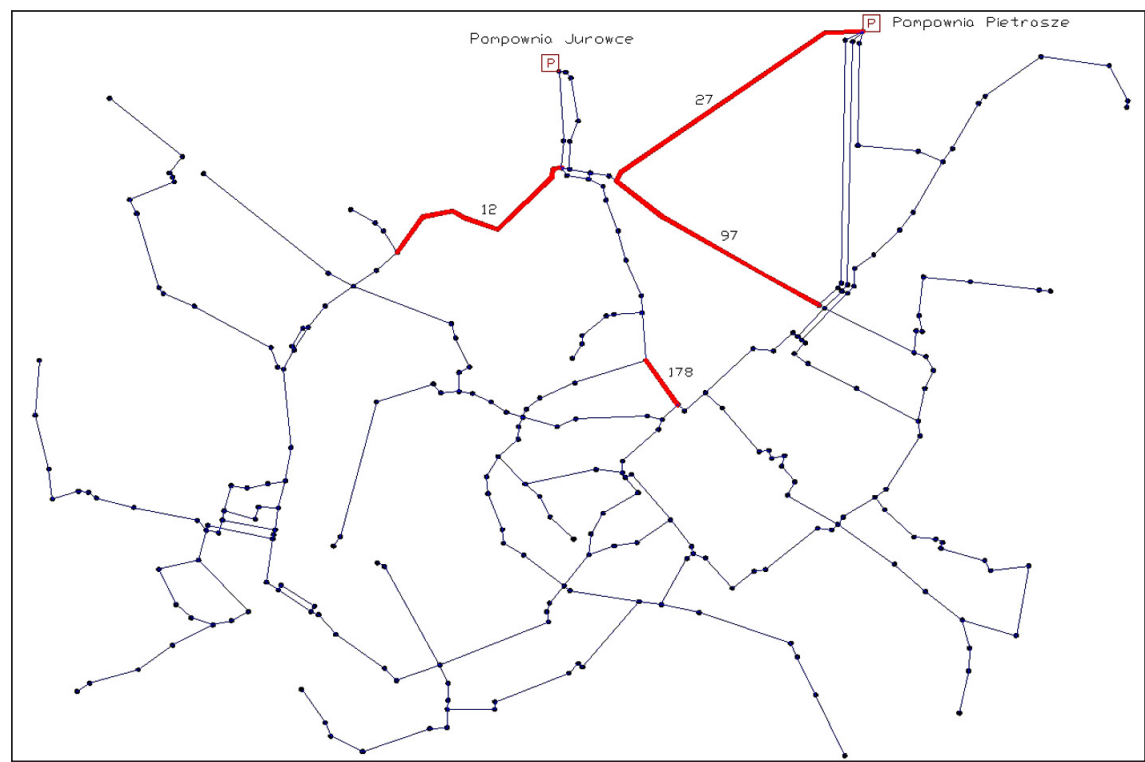

Figure 2. Diagram of the SDW of Bialystok with the variants of the C option highlighted

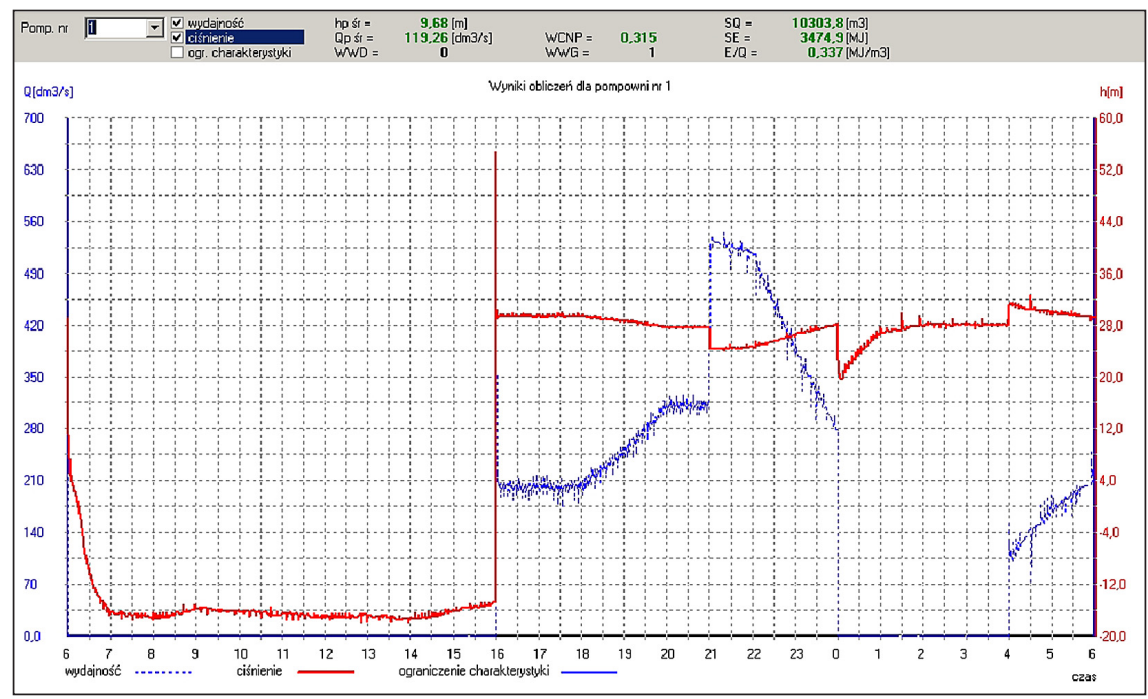

Figure 3. The diagram of the time course of the pump_P1 operation parameters in the Pietrasze pumping station (node No._1) for the C5 variant

thus minimal losses, there are many situations where even the moment of damage to one transit section does not cause a major disruption to the network. Because not all observed situations brought significant changes on the analysed model, the selection of the most representative series of all it was made.

The work presents variants of the $\mathrm{C} 5$ variant, which concerned the closing of segment 178 for 24 hours and the failure of pumps: P1, P2, P3 in node No. 1, in the hours: 6-16. Figure 3 and 4 illustrate the time course of parameters of emergency operation of pumps: P1, P2, P3 and P5 for the discussed variant and the value of changing WWPW, for the whole system and the time of simulation. As a result of the occurrences, a drop in the discharge pressure was noted on pumps: P1, P2 and P3 located at the Pietrasze station and at the same time reduced efficiency of their work. In turn, the Jurowce pumping station, in addition to being more efficient, also has an increasing discharge pressure, as well as slightly lower than that observed in the trouble-free operation of the system. It also shows the values of WCNP, which fall in relation to those obtained in option A. Global WWPW $(81.46 \%)$ indicates that in SDW unacceptable conditions of water abstraction begin to prevail. While observing this situation, large drops and differences between PWCW (71.1\%) and PWCP (53.6\%) were noticed, while 


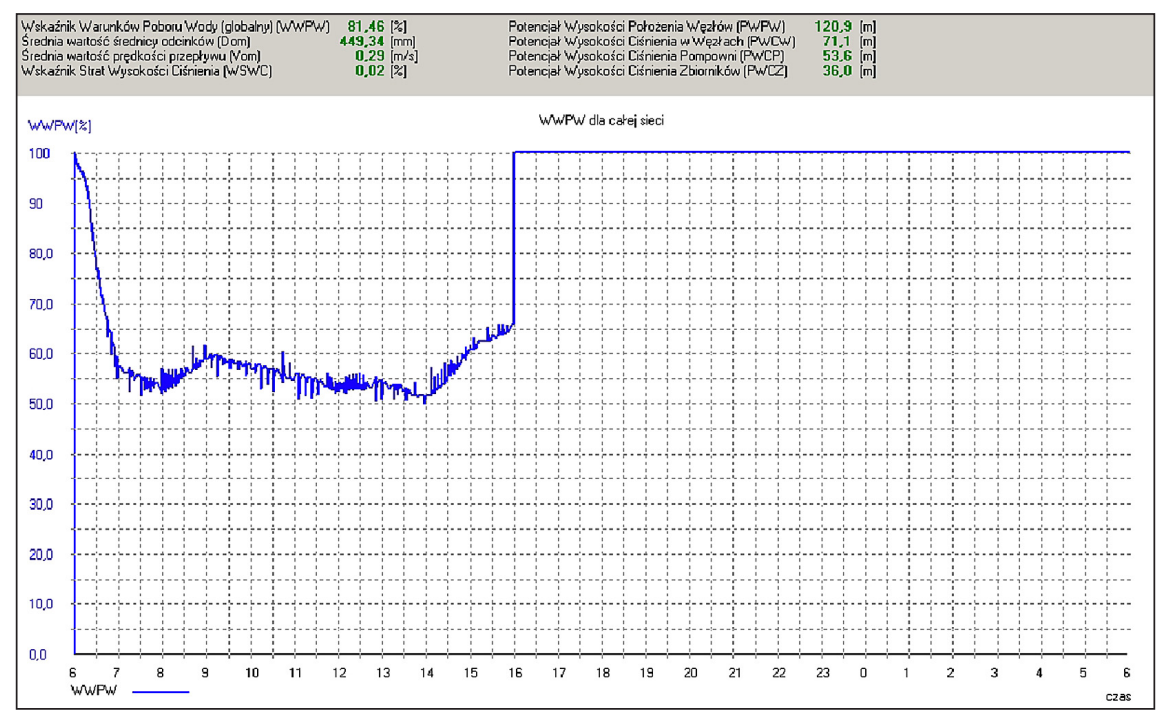

Figure 4. Chart for temporary changes of WWPW for option C5

a slight increase in the average flow rate causes a slight increase in the value of losses.

\section{CONCLUSIONS}

Working with a correctly designed and calibrated model enables to achieve huge savings resulting from the elimination of improper investments. Owing to computer simulations, it becomes possible to test different solutions, and compare the effects of each of them. The choice of solution depends on the fulfillment of technical and economic criteria. The development of computer techniques in recent years has led to the creation of powerful engineering tools, which undoubtedly are some of the programmes offered. Their use in practice to a large extent depends on the awareness and qualification of human resources, while the benefits are in fact immeasurable.

As a result of the conducted research on the variability over time of the characteristic parameters of the SDW water distribution system in Bialystok, the following conclusions were drawn:

1. The dynamics of the model allowed to obtain series of data regarding the operation of the SDW, in particular the cases of changes in the value of flow rate and water pressure and the SDW water response to the introduced modifications.

2. It has been observed that the flow rates deviate from those recommended depending on the diameter value. This is the result of a systematic decrease in water consumption in distribution systems generally throughout the country.
3. The oscillation of pumping systems, which appears in some situations, has become alarming, which in turn will help in eliminating and paying particular attention to the consequences.

4. The dominant feature of the obtained results of pressure measurements is its distinct variability over time. A balance of time has been obtained to balance the power supply and consumption. The effects of selected SDW states were determined by assessing the effectiveness of projects reducing their negative impact.

Introduction of the proposed simulation method, first of all, for the assessment of the consequences of occurring water distribution system failures will fill the gap which appeared while applying the methods of reliability assessment pertaining to the operation of water supply systems.

\section{Acknowledgements}

The research was carried out as part of project no. S/WBIIŚ/2/2014 thanks to financial support for research and science of the Ministry for Science and Higher Education.

\section{REFERENCES}

1. Abe N., Peter B.C. 2010. Epanet Calibrator - An integrated computational tool to calibrate hydraulic models. Integrating Water Systems Boxall \& Maksimovic.

2. Boulos P.F., Lansey K.E., Kamey B.W. 2009. Comprehensive Water Distribution Systems Analysis Handbook for Engineers and Planners, Pasadena, 
MWH Soft, California.

3. Darsono S., Labadie J.W 2007. Neural-optimal control algorithm for real-time regulation of in-line storage in combined sewer systems. Environmental Modelling \& Software, 22, 1349-1361.

4. Knapik K. 2000. Dynamiczne modele w badaniach sieci wodociągowych. Kraków.

5. Machón I., López H., Rodriguez-Iglesias J., Marañón E., Vázquez I. 2007. Simulation of a coke wastewater nitrification process using a feed-forward neuronal net. Environmental Modelling \& Software, 22, 1382-1387.

6. Mays L.W. 2005. The role of risk analysis in water resources engineering. Department of Civil and Environmental Engineering, Arizona State University. www.public.asu.edu/lwmays, 8-12.

7. Michaud D., Apostolakis G.E. 2006. Methodology for ranking elements of water supply networks. Journal of Infrastructure Systems, 12(4), 230-242.
8. Sadiq R., Saint-Martin E., Kleiner Y. 2008. Predicting risk of water quality failures in distribution networks under uncertainties Rusing fault-tree analysis. Urban Water, 5(4), 287-304.

9. Studziński J. 2014. Some algorithms supporting the water network management by use of simulation of network hydraulic model. Industrial Simulation Conference (ISC), 11-13.06.2014, Hoegskolan, EUROSIS 2014, 33-37.

10. Trębicka A. 2018. Dynamic model of the water distribution system as an analysis tool in the management of the Lapy water supply network. Economic and Environment, 3, 118-126.

11. Trębicka A. 2018. Efficiency and optimum decisions in the modeling process of water distribution. Journal of Ecological Engineering, 19(6), 254-258.

12. Walski T., Chase D.V., Sawicki D.A. 2011. Water distribution modeling. HaestadPress, Waterbury, CT, USA. 